Nat. Hazards Earth Syst. Sci., 21, 171-186, 2021

https://doi.org/10.5194/nhess-21-171-2021

(c) Author(s) 2021. This work is distributed under

the Creative Commons Attribution 4.0 License.

\title{
A methodology for attributing the role of climate change in extreme events: a global spectrally nudged storyline
}

\author{
Linda van Garderen ${ }^{1}$, Frauke Feser ${ }^{1}$, and Theodore G. Shepherd ${ }^{2}$ \\ ${ }^{1}$ Institute for Coastal Research - Analysis and Modelling, Helmholtz-Zentrum Geesthacht, \\ Max-Planck-Straße 1, 21502 Geesthacht, Germany \\ ${ }^{2}$ Department of Meteorology, University of Reading, Reading RG6 6BB, United Kingdom
}

Correspondence: Linda van Garderen (linda.vangarderen@hzg.de)

Received: 5 June 2020 - Discussion started: 26 June 2020

Revised: 25 September 2020 - Accepted: 26 November 2020 - Published: 18 January 2021

\begin{abstract}
Extreme weather events are generally associated with unusual dynamical conditions, yet the signal-to-noise ratio of the dynamical aspects of climate change that are relevant to extremes appears to be small, and the nature of the change can be highly uncertain. On the other hand, the thermodynamic aspects of climate change are already largely apparent from observations and are far more certain since they are anchored in agreed-upon physical understanding. The storyline method of extreme-event attribution, which has been gaining traction in recent years, quantitatively estimates the magnitude of thermodynamic aspects of climate change, given the dynamical conditions. There are different ways of imposing the dynamical conditions. Here we present and evaluate a method where the dynamical conditions are enforced through global spectral nudging towards reanalysis data of the large-scale vorticity and divergence in the free atmosphere, leaving the lower atmosphere free to respond. We simulate the historical extreme weather event twice: first in the world as we know it, with the events occurring on a background of a changing climate, and second in a "counterfactual" world, where the background is held fixed over the past century. We describe the methodology in detail and present results for the European 2003 heatwave and the Russian 2010 heatwave as a proof of concept. These show that the conditional attribution can be performed with a high signal-tonoise ratio on daily timescales and at local spatial scales. Our methodology is thus potentially highly useful for realistic stress testing of resilience strategies for climate impacts when coupled to an impact model.
\end{abstract}

\section{Introduction}

There is increasing interest in understanding and quantifying the impact of climate change on individual extreme weather and climate events. This is to be distinguished from detecting the effect of climate change on the statistics of extreme events (IPCC, 2012). In the most commonly used approach, changes in the probability distribution of an event class, whose definition is motivated by a historical event, are calculated by simulating large ensembles with an atmosphereonly climate model (Watanabe et al., 2013). The changes are computed between the "factual" ensemble, corresponding to observed forcings (e.g. sea-surface temperatures (SSTs) and greenhouse-gas (GHG) concentrations), and a "counterfactual" ensemble, corresponding to an imagined world without climate change. The latter is usually constructed by removing an estimate of the forced changes in SSTs and imposing pre-industrial GHG concentrations. As discussed by Shepherd (2016), this probabilistic approach has two prominent limitations. The first is that every extreme event is unique, but the construction of a general event class blurs the connection to the actual event and makes it difficult to link the event attribution to climate impacts. This is important because extreme impacts are not always associated with extreme meteorology (van der Wiel et al., 2020). The second limitation is that extreme events are generally associated with extreme dynamical conditions, and there is little understanding, let alone agreement, on how those dynamical conditions might respond to climate change (Hoskins and Woollings, 2015; Shepherd, 2014). This represents an uncertainty in the probabilistic estimates that is difficult to quantify. 
On the other hand, thermodynamic aspects of climate change such as warming and increasing specific humidity are robust in sign, anchored in agreed-upon physical understanding, and clearly emerging in observations (IPCC, 2018). Moreover in many cases the signal-to-noise ratio of the forced dynamical changes appears likely to be small (Deser et al., 2016; Schneider et al., 2012). Thus, although dynamical and thermodynamic processes are interwoven in the real climate system, it can be useful to regard the uncertainties in their forced response to climate change as being separable, at least to a first approximation. This has been a growing theme in climate change attribution over the past few decades. The distinction between thermodynamic and dynamical changes is not precise, and various ways of implementing the separation diagnostically have been used in different contexts. For extratropical regional climate, it has been common to regard the component of change congruent with large-scale internal variability (e.g. as defined by empirical orthogonal functions or by self-organizing maps) as "dynamical" (Deser et al., 2016; Horton et al., 2015) and the residual as "thermodynamic". For tropical climate or for extratropical storms, dynamical changes are instead commonly identified with changes in vertical velocity (Bony et al., 2013; Pfahl et al., 2017). In the absence of evidence to the contrary, a reasonable hypothesis is that the forced dynamical changes are undetectable; this hypothesis is implemented explicitly in the "pseudo global warming" methodology used for regional climate studies (Schär et al., 1996) and in the "dynamical adjustment" methodology used to study observed climate trends (Wallace et al., 2012).

Trenberth et al. (2015) suggested that the same thinking could be usefully applied to the attribution of individual extreme events. Specifically, the extreme dynamical circumstances leading to the event could be regarded as given, i.e. arising by chance, and the question posed of how the event was modified by the known thermodynamic aspects of climate change. This conditional framing of the attribution question was subsequently dubbed the "storyline" approach (Shepherd, 2016) and has a precedent in the application of dynamical adjustment to extreme seasonal climate anomalies (Cattiaux et al., 2010). As emphasized by Shepherd (2016) and NAS (2016), there is actually a continuum between the storyline and probabilistic approaches: storylines are highly conditioned probabilities, and probabilistic approaches generally involve some form of dynamical conditioning too, through the imposed SST patterns. However, the extent of conditioning imposed by constraining the atmospheric state is so severe that in practice the storyline approach can be regarded as deterministic, just as weather forecasts, whilst probabilistic in principle, are interpreted deterministically when the ensemble spread is sufficiently narrow.

By focusing on the known effects of climate change, the storyline approach seeks to avoid "Type 2" errors or missed warnings, in contrast to the probabilistic approach, which, by needing to reject the null hypothesis of no climate change whatsoever, seeks to avoid "Type 1" errors or false alarms (Lloyd and Oreskes, 2018; Trenberth et al., 2015). A colloquial way of putting this is that rather than asking what extreme events can tell us about climate change, we ask what known aspects of climate change can tell us about particular extreme events. Although its results are not expressed probabilistically, the storyline approach enables a quantitative estimate of climate change with a clear causal interpretation (Pearl and Mackenzie, 2018). Notwithstanding the need for asking both kinds of questions as they provide different kinds of information (Lloyd and Shepherd, 2020), the storyline approach is a new development, and there are as yet not so many studies employing this approach.

In previous applications of the storyline approach, individual extreme weather events have been dynamically constrained through boundary conditions applied to a regional model (Meredith et al., 2015) or by controlling the initial conditions in a weather forecast model (Patricola and Wehner, 2018). More recently, nudging the free atmosphere to reanalysis data (leaving the boundary layer free to respond) has been applied in a global medium-resolution atmospheric model to constrain the dynamical conditions leading to heatwaves, first to determine the effect of soil moisture changes on selected recent heatwaves (Wehrli et al., 2019) and subsequently to determine the effect of past and projected future warming on the 2018 Northern Hemisphere heatwave (Wehrli et al., 2020). The concept of nudging the atmospheric circulation in order to impose the dynamical conditions has a long history. In particular, spectral nudging (von Storch et al., 2000; Waldron et al., 1996) allows for scale-selective nudging so that only the large spatial scales of the model are constrained, while the smaller scales, including those relevant to extreme events, are free to be simulated by the high-resolution model. The climate model can thus potentially add value and regional detail to the coarserresolution forcing dataset. Spectral nudging has been used in regional climate modelling (Feser and Barcikowska, 2012; Scinocca et al., 2015) and in boundary-layer sensitivity studies (van Niekerk et al., 2016). Note that in all these modelling approaches, the dynamical constraint is imposed "remotely" from the phenomenon of interest (in space, time, and/or spatial scale) in contrast to the diagnostic approaches mentioned earlier and thus preserves the physical interplay between dynamics and thermodynamics within the extreme event itself.

The purpose of this paper is to provide a methodological underpinning for the application of large-scale spectral nudging of divergence and vorticity in a global highresolution atmospheric model for the purpose of attributing the role of thermodynamic aspects of climate change (or other conditional perturbations) in extreme events of various types and timescales. A key question is to determine what level of refinement of the attribution, in both space and time, is possible. The outline of the paper is as follows. In Sect. 2, we elaborate on the technicalities of spectral nudging within the ECHAM6 model and its parameter sensitiv- 
ities as well as the construction of the counterfactual simulations. In Sect. 3, we exemplify the method by applying it to two well-studied heatwaves: the European 2003 heatwave and the Russian 2010 heatwave. As well as identifying some important differences between the two events, we examine the signal-to-noise ratio of our attribution. A concluding discussion follows in Sect. 4.

\section{Method}

\subsection{Spectral nudging}

The spectral-nudging technique is well established within the context of regional climate modelling (Miguez-Macho et al., 2004; von Storch et al., 2000, 2018; Waldron et al., 1996). In this approach, so-called "nudging terms" are added to the large-scale part of the climate model trajectory, which draws the model towards reanalysis data. Global spectral nudging (Kim and Hong, 2012; Schubert-Frisius et al., 2017; Yoshimura and Kanamitsu, 2008) works in a similar way. It constrains large-scale weather patterns of the climate model, such as high- and low-pressure systems or fronts, to stay close to reanalysis data in order to derive a global highresolution weather reconstruction. The general idea is that the realistic large-scale state of the reanalysis data is followed by the global climate model (GCM), while at smaller scales the model provides additional detail to improve highresolution weather patterns. Another merit of the approach is the potential to reduce inhomogeneities in the dataset by using only a very limited number of variables from the reanalysis data, although this is less of an issue for our application because we compare factual and counterfactual simulations for the same large-scale conditions, so any inhomogeneity in the reanalysis would apply equally to both. For the same reason, our approach can be expected to be robust to any differences between reanalyses. In order to define a noise level for our analysis, we construct small ensembles of three factual and three counterfactual simulations. Although such small ensembles are clearly inadequate for quantifying conditional probabilities, they have been successfully used in the past (e.g. Shepherd, 2008) to identify robust differences between the two ensembles from a deterministic perspective, which is our interest here.

\subsection{ECHAM6 application}

For this study, we use the high-resolution T255L95 GCM ECHAM6 (Stevens et al., 2013) with the JSBACH land component sub-model (Reick et al., 2013); however the method is applicable to any atmospheric GCM. SSTs and sea ice concentrations (SICs) are prescribed from NCEP1 reanalysis data (Kalnay et al., 1996). ECHAM6 is globally spectrally nudged towards the NCEP1 reanalysis data to achieve realistic weather patterns and extreme events of the past. However, any other reanalysis should provide similar results since only the large-scale fields are nudged. We chose NCEP1 due to its starting date in 1948, which is earlier than any of the other reanalysis data, enabling application of our method over a longer period of time. It is conceivable that for certain kinds of extreme events involving a tight coupling between resolved and parameterized processes, ensuring consistency between the reanalysis and the model would be beneficial. In a previous application nudging was applied for pressure, temperature, vorticity, and divergence (Jeuken et al., 1996) with a constant height profile throughout the entire atmosphere. However, we want to reproduce only the large-scale atmospheric circulation and in particular leave the thermodynamic fields (temperature and moisture) free to respond; hence we only nudge vorticity and divergence in the free atmosphere. The aim is to constrain the model as little as possible so that it can freely develop small-scale meteorological processes and extreme events while still achieving an effective control of the large-scale weather situation.

The nudging of variable $X$ over time is applied in the spectral domain as follows (adapted from Jeuken et al., 1996):

$\frac{\partial X}{\partial t}=\left\{\begin{array}{ll}F_{X}+G\left(X_{\mathrm{NCEP}}-X\right) & \text { for } n \leq 20, p<750 \mathrm{hPa} \\ F_{X} & \text { otherwise }\end{array}\right.$,

where $X$ is the variable to be nudged (either vorticity or divergence), $F_{X}$ is the model tendency for variable $X$, and $X_{\text {NCEP }}$ is the state of that variable in NCEP1. The thresholds $p$ and $n$ need to be met for nudging to happen, namely pressure $p$ must be below $750 \mathrm{hPa}$, and the spherical harmonic index $n$ must not exceed 20. $G$ is the relaxation coefficient in units of $10^{-5} \mathrm{~s}^{-1}$ determining the nudging strength. Nudging is performed at every time step.

We applied most settings according to Schubert-Frisius et al. (2017), including the usage of spectral nudging in both meridional and zonal directions. We use a plateau nudging-strength height profile (see Fig. 1a), which starts at $750 \mathrm{hPa}$, then quickly increases up to its maximum nudging strength, and stays there for higher tropospheric and lower and medium stratospheric levels until it again quickly tapers back to 0 at a height corresponding to $5 \mathrm{hPa}$. The reason for the latter choice is that above $5 \mathrm{hPa}$ there is no NCEP1 reanalysis data available.

The strength of nudging is determined by the relaxation coefficient $\left(G\right.$; in $\left.10^{-5} \mathrm{~s}^{-1}\right)$; see Eq. (1). The relaxation coefficient is often described using the e-folding time $\left(G^{-1}\right.$; in $10^{5} \mathrm{~s}$ ) which represents the simulated time necessary for nudging to dampen out a model-introduced disturbance. For example, if the e-folding time is $10 \mathrm{~h}$ then the nudged model will dampen out that disturbance (with an assumed amplitude of 1) to a value of $1 / e$ and thus greatly reduce it within $10 \mathrm{~h}$. A larger relaxation coefficient implies a stronger nudging and translates into a shorter e-folding time or dampening time (von Storch et al., 2000). We have tested several e-folding times to see if the settings could be further relaxed and still reproduce the large-scale weather conditions. In Fig. $1 \mathrm{~b}$ the impact of the tested e-folding time settings on the temporal 

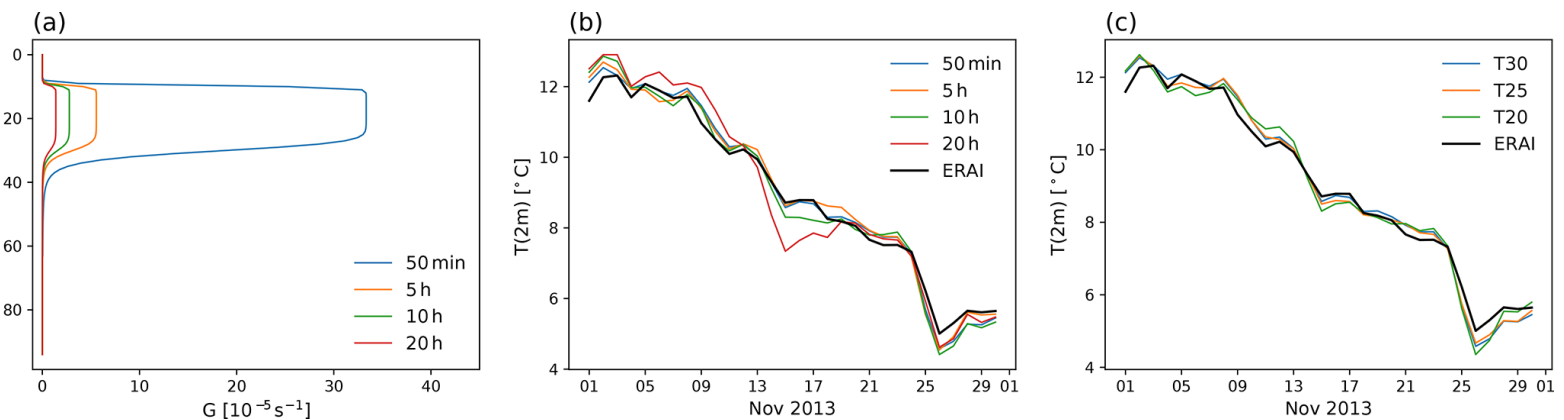

Figure 1. (a) Nudging strength $G\left[10^{-5} \mathrm{~s}^{-1}\right]$ as a function of model level for different choices of minimum e-folding time as indicated. (b) Daily mean temperatures at $2 \mathrm{~m}$ height $\left[{ }^{\circ} \mathrm{C}\right]$ of ECHAM6 in November 2013 averaged over the European domain $\left(35-60^{\circ} \mathrm{N}, 10^{\circ} \mathrm{W}-\right.$ $35^{\circ} \mathrm{E}$ ) using the different e-folding times shown in (a) in comparison to ERA-Interim. (c) Daily mean temperatures as in (b) but with a 50 min nudging timescale at different truncations again in comparison to ERA-Interim.

evolution of the $2 \mathrm{~m}$ temperature averaged over Europe (35$60^{\circ} \mathrm{N}, 10^{\circ} \mathrm{W}-30^{\circ} \mathrm{E}$ ) in comparison to ERA-Interim is shown through November 2013. There is little difference visible between the $50 \mathrm{~min}$ and $5 \mathrm{~h}$ e-folding times. The $10 \mathrm{~h}$ results start to show small deviations, whilst the $20 \mathrm{~h}$ results deviate even more noticeably. On the basis of this sensitivity study, we conclude that the e-folding time can safely be relaxed from $50 \mathrm{~min}$ to $5 \mathrm{~h}$ without losing the accuracy of the results.

We similarly aim to limit the range of spatial scales being nudged as much as possible. In Fig. 1c we show the $2 \mathrm{~m}$ temperature results for the different nudging wavelengths in comparison to ERA-Interim. The original $T_{30}$ settings used by Schubert-Frisius et al. (2017), which translate to a minimum wavelength of approximately $1300 \mathrm{~km}\left(360^{\circ} / 30 \times\right.$ $111 \mathrm{~km}$ ), show comparable results to the $T_{25}$ and $T_{20}$ resolutions. The nudging was therefore relaxed to the $T_{20}$ resolution, which translates to a minimum wavelength of approximately $2000 \mathrm{~km}\left(360^{\circ} / 20 \times 111 \mathrm{~km}\right)$. This should be sufficient to resolve the large-scale circulation while allowing smaller-scale processes related to local weather events to develop freely. In Fig. 2 the geopotential height anomalies for summer 2010 in the factual and counterfactual simulations show a strong resemblance. Even though the background conditions of the two simulations are different (which is further explained in Sect. 2.3), the blocking pattern formed over Russia in 2010 is clearly present in both simulations, demonstrating the capability of our nudging method to reproduce the complex dynamical situation.

We used ECHAM_SN throughout this paper to calculate climatological data for comparison to our own findings. The ECHAM_SN dataset is a spectrally nudged global historical simulation from 1948-2015 (Schubert-Frisius et al., 2017). It nudged vorticity and divergence towards NCEP1 in a vertical plateau-shaped profile, equal to the profile we use, at spatial scales corresponding to $T_{30}$ or larger, with an e-folding time of $50 \mathrm{~min}$.
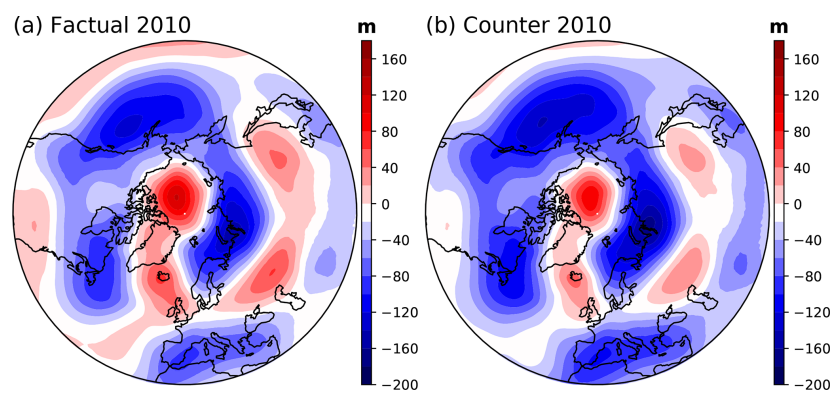

Figure 2. Geopotential height $\left(z_{500}\right)$ June-July-August (JJA) anomalies [m] for the Northern Hemisphere showing the averaged spectrally nudged dynamic situation over (a) factual members and (b) counterfactual members of the summer 2010 blocking. Anomalies were calculated relative to the ECHAM_SN 1980-2014 JJA climatology.

\subsection{Simulating the counterfactual}

In this study, as in probabilistic event attribution, counterfactual and factual climate simulations are used to assess the effect of climate change on extreme events. Factual is defined as the world as we know it or a historical simulation. Counterfactual is defined as an imagined modern world without climate change. In our simulations, land use and volcanic activity as well as aerosol forcing and sea ice concentration are unchanged between factual and counterfactual. The differences between the two worlds are created by altering two important aspects of the simulation: (a) sea-surface temperature (SST) and (b) greenhouse gases (GHG). Both worlds are spectrally nudged in the same way. A potential way to check the results of the counterfactual simulation, especially for simulations over a longer time span, is to study the consistency between the inferred signals of climate change for smaller climate forcings (e.g. since mid-century) and the attributed changes in the observational record. Our simulations are 5 years each and therefore cannot be tested in this way. 
However for longer simulations such a test would be beneficial.

SST patterns such as the Atlantic Multidecadal Oscillation or El Niño greatly influence weather extremes. Therefore, as with probabilistic event attribution, we impose the same SST variability for both the factual and counterfactual simulation, based on the observed SST pattern. (However, this is expected to be less critical in our case since we are imposing the large-scale atmospheric circulation.) We create the counterfactual SST conditions by subtracting a climatological warming pattern from the observed pattern, which is a standard procedure in probabilistic event attribution studies (Otto, 2017; Vautard et al., 2016; Stott et al., 2016). Although it is common to consider different climatological warming patterns as a means of exploring uncertainty, this is not so relevant in our case since the large-scale circulation is imposed. The climatological warming pattern is computed using the ECHAM6 CMIP6 (MPI-ESM1.2-HR) control and historical simulations at an atmospheric resolution of $T_{127}$ (Müller et al., 2018). The procedure is shown in Eq. (2):

$\mathrm{SST}_{t, \mathrm{c}}=\mathrm{SST}_{t}^{\mathrm{NCEP} 1}-\left(\mathrm{SST}_{t, \mathrm{~h}}^{\mathrm{CMIP6}}-\mathrm{SST}_{t, \mathrm{pi}}^{\mathrm{CMIP} 6}\right)$,

where $\mathrm{SST}_{t, \mathrm{c}}$ is the counterfactual SST at time $t, \mathrm{SST}_{t}^{\mathrm{NCEP} 1}$ is the NCEP1 SST at time $t, \mathrm{SST}_{t, \mathrm{~h}}^{\mathrm{CMIP}}$ is the CMIP6 historical SST at time $t$, and SST $\mathrm{S}_{t, \mathrm{pi}}^{\mathrm{CM}}$ is the CMIP6 pre-industrial SST at time $t$ (for the latter, the only relevant time dependence would be seasonal). In our present implementation, which targets boreal summer only and concerns only a fairly short time period, the seasonal time dependence is suppressed, and the historical CMIP SSTs are taken to be the 2000-2009 average. For a simulation covering a full year the warming pattern should be made seasonal, and for one covering several decades it would furthermore need to be weighted over time. In Fig. 3 the CMIP6 SST warming pattern shows a good resemblance to the observed HadSST3 warming pattern. The HadSST3 pattern is obtained by subtracting the 1880-1890 average from the 1980-1990 average SST values. The general warming and cooling patches in the Pacific Ocean and Atlantic Ocean south of Greenland agree well. Also, the warming north of Scandinavia is clearly visible in both warming patterns. Despite the observational data-void region east of Greenland and north of Iceland, there is a good resemblance of our modelled warming pattern with observations. Note that pre-industrial SST observations were dependent upon ship records, which in the polar region were very few (Rayner et al., 2006), causing this part of the observational dataset to be incomplete.

For technical reasons, we did not alter the SIC in the counterfactual simulations. Given that the atmospheric circulation is nudged, changes in SIC are not expected to be relevant for summertime heatwaves as Arctic amplification from sea ice loss is a wintertime phenomenon (Screen and Simmonds, 2010). In Fig. 4 the counterfactual SSTs for July 2003 and July 2010 are shown together with the factual
Table 1. Greenhouse-gas concentrations for the ECHAM6 counterfactual simulations.

\begin{tabular}{ll}
\hline Greenhouse gas & Concentration \\
\hline Carbon dioxide $\left(\mathrm{CO}_{2}\right)$ & $285 \mathrm{ppmv}$ \\
Methane $\left(\mathrm{CH}_{4}\right)$ & $790 \mathrm{ppbv}$ \\
Nitrous oxide $\left(\mathrm{N}_{2} \mathrm{O}\right)$ & $275 \mathrm{ppbv}$ \\
Chlorofluorocarbons $(\mathrm{CFCs})$ & 0 \\
\hline
\end{tabular}

SIC. This shows that the sea ice edge is well away from the European and western Russian domains. Moreover, even under counterfactual conditions the SST remains almost completely physically self-consistent with the SIC according to the constraints of Hurrell et al. (2008); in particular, there are only a very few isolated regions where the SST falls below $-2{ }^{\circ} \mathrm{C}$. Nevertheless, we tested the impact of altering SIC in a counterfactual simulation of the Russian heatwave based on the counterfactual SSTs, using the linear relation found by Hurrell et al. (2008). Specifically, SIC was set to $100 \%$ for SSTs below $-1.7^{\circ} \mathrm{C}$ and to $0 \%$ for SSTs above $3^{\circ} \mathrm{C}$, with a linear interpolation in between. The results show no differences compared to the unaltered SIC counterfactual members (see Fig. 5b). However, to apply our method to other seasons or regions in close proximity to areas of sea ice loss, the counterfactual simulations would benefit from including SIC changes in the same way as was done with SST.

In the factual simulation the GHGs change according to observed values (Meinshausen et al., 2011). In the counterfactual simulation, GHGs remain at their 1890 values as listed in Table 1. This means that, strictly speaking, our attribution is to the combined effects of anthropogenic climate change (including aerosol forcing) recorded in the SSTs as well as the direct radiative effects of GHG forcing.

The default initial atmospheric state of the ECHAM6 model is a random state during the simulated mid-1990s. Changing that initial state to a counterfactual initial state requires a spin-up time to allow the atmosphere and land surface enough time to reach a new equilibrium state with their new boundary conditions. To accomplish this we run a nonnudged counterfactual spin-up ensemble for 3 model years with three members. We chose a 3-year spin-up after confirming the soil moisture was adapted to the new counterfactual situation (not shown). Each member was initiated at a different starting date (January-March 1995). The results of these spin-ups are three random atmospheric counterfactual states, which are used as initial conditions for the counterfactual experiments. Although in principle both the factual and counterfactual conditions define conditional probabilities, our three-member ensembles are certainly not sufficient to estimate those probabilities. As noted earlier, our goal here is simply to determine the robustness of the deterministic differences between the factual and counterfactual ensembles. 

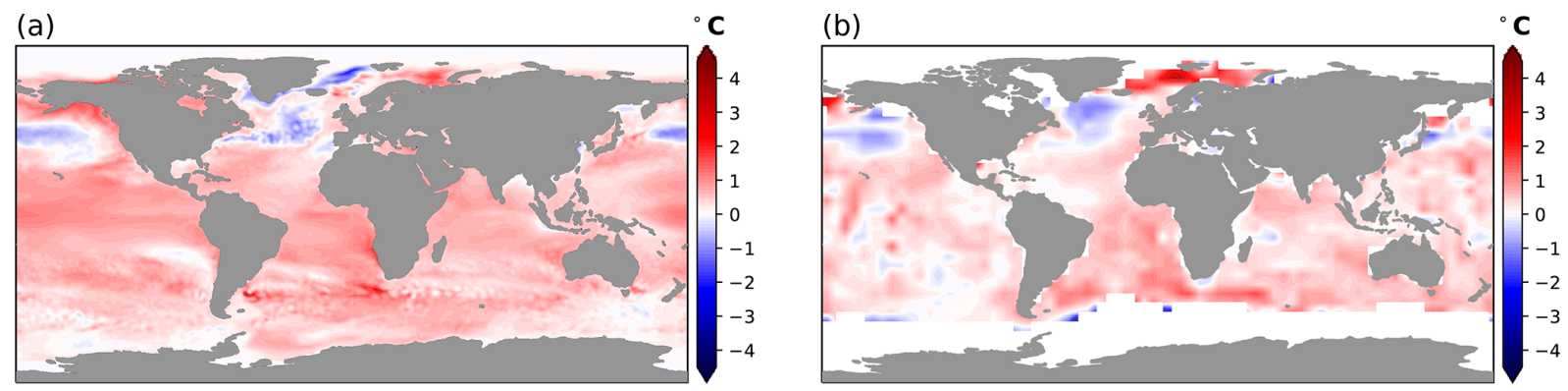

Figure 3. Sea-surface temperature (SST) warming pattern $\left[{ }^{\circ} \mathrm{C}\right]$ calculated (a) from ECHAM6 CMIP6 modelled data and (b) from HadSST3 observed data.

(a) July 2003

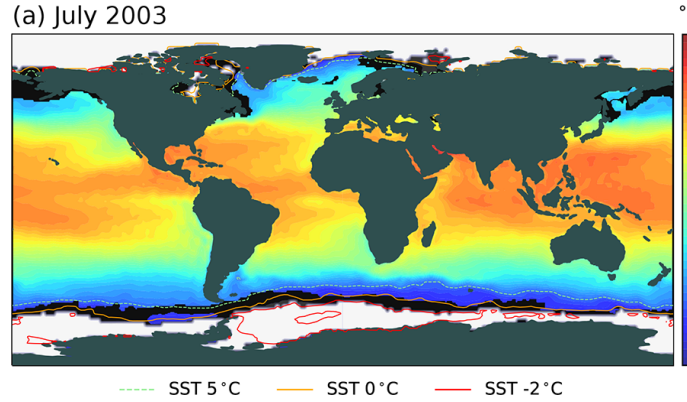

${ }^{\circ} \mathbf{C} \quad \% \quad$ (b) July 2010
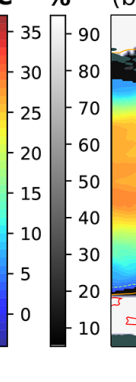

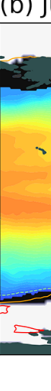

${ }^{\circ} \mathrm{C}$

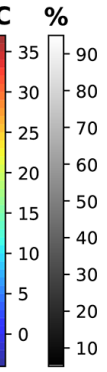

SST $5^{\circ} \mathrm{C}-\mathrm{SST} 0^{\circ} \mathrm{C}-\mathrm{SST}-2^{\circ} \mathrm{C}$

Figure 4. Counterfactual SST $\left[{ }^{\circ} \mathrm{C}\right]$ in shaded colours and factual SIC [\%] in greyscale for (a) July 2003 and (b) July 2010 . The SST $5{ }^{\circ} \mathrm{C}$ (dashed green), $0{ }^{\circ} \mathrm{C}$ (orange), and $-2{ }^{\circ} \mathrm{C}$ (red) contours are marked for reference.

The ECHAM_SN simulation and the altered SIC simulation provide out-of-sample tests of robustness for the factual and counterfactual ensembles, respectively. Figure 5 shows that in both cases, these simulations fall largely within the range of the three-member ensembles.

For the European 2003 heatwave the three counterfactual members run from 1 March and are initialized with the spin-up counterfactual atmospheric state members (year 3 , March). The three factual members are started 1 month apart from each other (in January-March 2003), and initialized with the corresponding atmospheric state from the ECHAM_SN dataset. For the Russian 2010 heatwave the three counterfactual members run instead from 1 January because of the known importance of soil preconditioning for this event (Wehrli et al., 2019). The three factual members again run with 1-month differences in their starting dates, but here from November 2009, December 2009, and January 2010, again initialized with the corresponding state from the ECHAM_SN dataset. For analysis regions we select $35-50^{\circ} \mathrm{N}, 10^{\circ} \mathrm{W}-25^{\circ} \mathrm{E}$ as the domain for the European heatwave 2003 and $50-60^{\circ} \mathrm{N}, 35-55^{\circ} \mathrm{E}$ for the Russian heatwave 2010, in line with previous literature (Dole et al., 2011; García-Herrera et al., 2010; Otto et al., 2012; Rasmijn et al., 2018; Wehrli et al., 2019).

For the summer of 2003, the global temperature difference between factual and counterfactual simulations is $0.64{ }^{\circ} \mathrm{C}$, while for the summer of 2010 the difference is $0.66^{\circ} \mathrm{C}$. From observations we know that the earth has experienced a global warming of approximately $0.7-0.8^{\circ} \mathrm{C}$ between preindustrial times and 2010 (IPCC, 2018). Our modelled global warming, found through the difference between the factual and counterfactual simulations, thus represents this difference well, albeit with a slight underestimation.

\section{Results}

To illustrate our method, we provide two examples, namely the European heatwave of 2003 and the Russian heatwave of 2010. These events are considered the two strongest European heatwaves on record (Russo et al., 2014, 2015). In Sect. 3.3 we look deeper into the signal-to-noise ratio of each of the examples and how they compare to each other.

\subsection{European heatwave 2003}

The European summer of 2003 was exceptionally hot and exceptionally dry (Black et al., 2004; Schär et al., 2004; Stott et al., 2004). Two heatwaves occurred, a milder one in June and an extreme heatwave in August, with peak temperatures in France and Switzerland (Black et al., 2004; Schär et al., 2004; Trigo et al., 2005) but also affecting Portugal, northern Italy, western Germany, and the UK (Feudale and Shukla, 2011a; Muthers et al., 2017). Temperatures exceeded the $1961-1990$ average by $2.3-12.5^{\circ} \mathrm{C}$, depending on loca- 

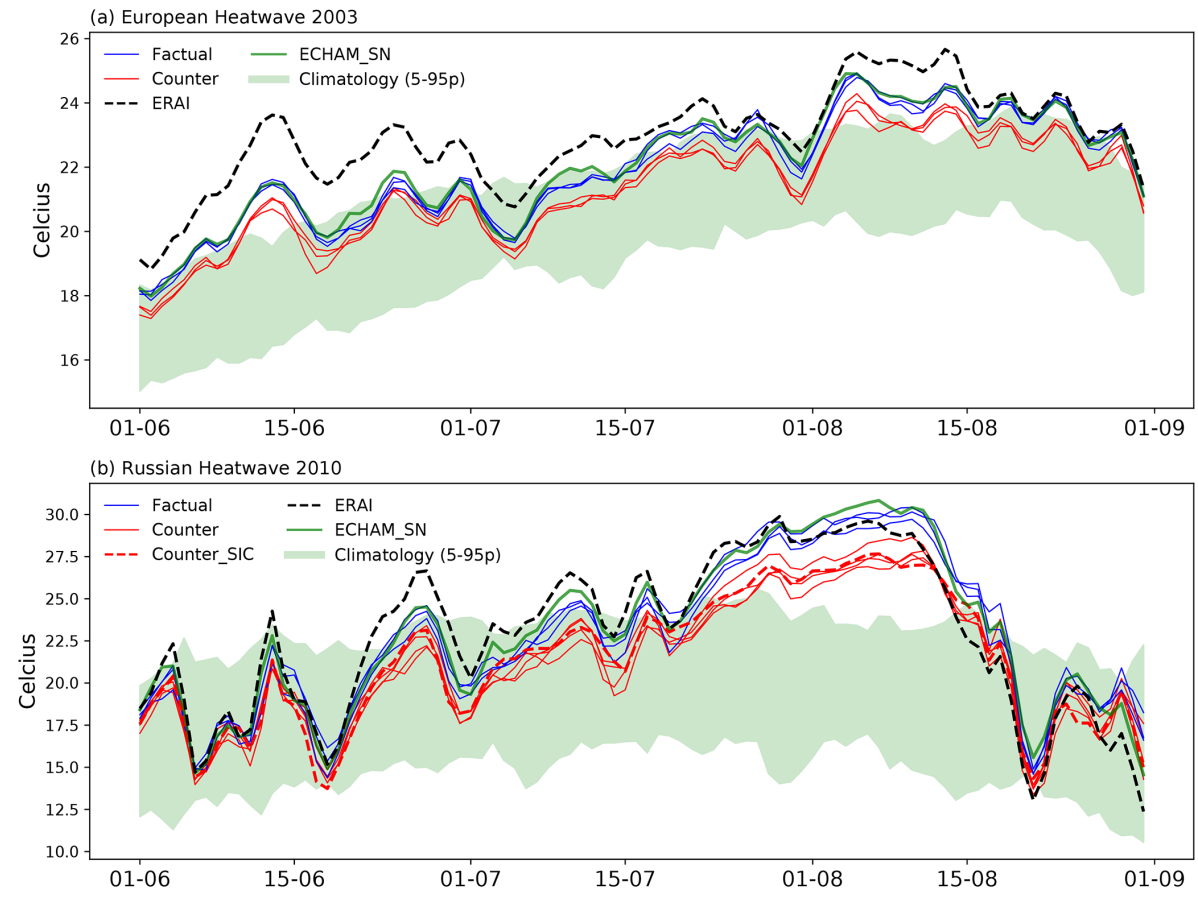

Figure 5. Daily mean temperature at $2 \mathrm{~m}$ height $\left[{ }^{\circ} \mathrm{C}\right]$ averaged over (a) Europe $\left(35-50^{\circ} \mathrm{N}, 10^{\circ} \mathrm{W}-25^{\circ} \mathrm{E}\right)$ for summer 2003 and over $(\mathbf{b})$ Russia $\left(50-60^{\circ} \mathrm{N}, 35-55^{\circ} \mathrm{E}\right)$ for summer 2010 for the factual (blue), counterfactual (red), and ECHAM_SN (green) simulations and ERAInterim (dashed black) reanalysis data. The climatology (green shaded area) is the 5th-95th ranked percentile range between 1985-2015 calculated with ECHAM_SN (Schubert-Frisius et al., 2017). The dashed red line in (b) shows the simulation with SIC changed in one of the counterfactual simulations (see text for details).

tion, without much cooling during the night (García-Herrera et al., 2010; Schär et al., 2004; Stott et al., 2004; Muthers et al., 2017). The 2003 summer was at that point in time not just the hottest on record (Bastos et al., 2014; Fink et al., 2004), it was the hottest summer in the past 500 years (Luterbacher et al., 2004). The consequences were devastating. Estimates account for $22000-40000$ heat-related deaths, USD 12-14 billion in economic losses, $20 \%-30 \%$ decrease in net primary productivity (NPP), $5 \%-10 \%$ of Alpine glacier loss, and many more human-health-related issues due to increased surface ozone concentrations (Ciais et al., 2005; Fischer et al., 2007; García-Herrera et al., 2010).

Both the June and August heatwaves were caused by stationary anticyclonic circulations or blocking (Black et al., 2004). The first block formed in June, then broke and quickly reformed in July, which then caused the second heatwave in August (García-Herrera et al., 2010). However, the extreme temperatures cannot be explained by atmospheric blocking alone. Due to large precipitation deficits in spring that year, the heatwaves happened in very dry conditions. The lack of clouds and soil moisture caused latent heat transfer to turn into sensible heat transfer, which dramatically increased surface temperatures (Bastos et al., 2014; Ciais et al., 2005; Fischer et al., 2007; Fink et al., 2004; Miralles et al., 2014). It is considered highly unlikely that the 2003 European heatwaves would have reached the temperatures they did with- out climate change (Hannart et al., 2016; Schär et al., 2004; Stott et al., 2004). The probabilistic event attribution studies show an increased likelihood of the extreme temperatures from increased GHGs (Hannart et al., 2016; Schär et al., 2004; Stott et al., 2004). Other studies focused on the exceptionally high SSTs in the Mediterranean Sea and North Sea as a cause of reduced baroclinicity, providing an environment conducive to blocking (Black et al., 2004; Feudale and Shukla, 2011a, b). By applying the storyline approach, we can consider both causal factors together and shed some additional insight on this event. The dry spring leading up to the warm summer conditions was captured by initializing the simulations by 1 March at the latest.

In Fig. 5a, the daily evolution of the domain-averaged temperature at $2 \mathrm{~m}$ height for June-August for each of the ensemble members is plotted in comparison to the ECHAM_SN 5th-95th-percentile (1985-2005) climatology and ERA-Interim (Dee et al., 2011). The ECHAM_SN 2003 temperature is also plotted for reference and shows a strong coherence with the factual ensemble, confirming the appropriateness of using the ECHAM_SN climatology as a reference for our factual simulations. The first thing to note is that the factual and counterfactual ensembles evolve very similarly in time but (except for the third week of June) are well separated, by approximately $0.6^{\circ} \mathrm{C}$, indicating a high signal-to-noise ratio at daily resolution for the domain av- 

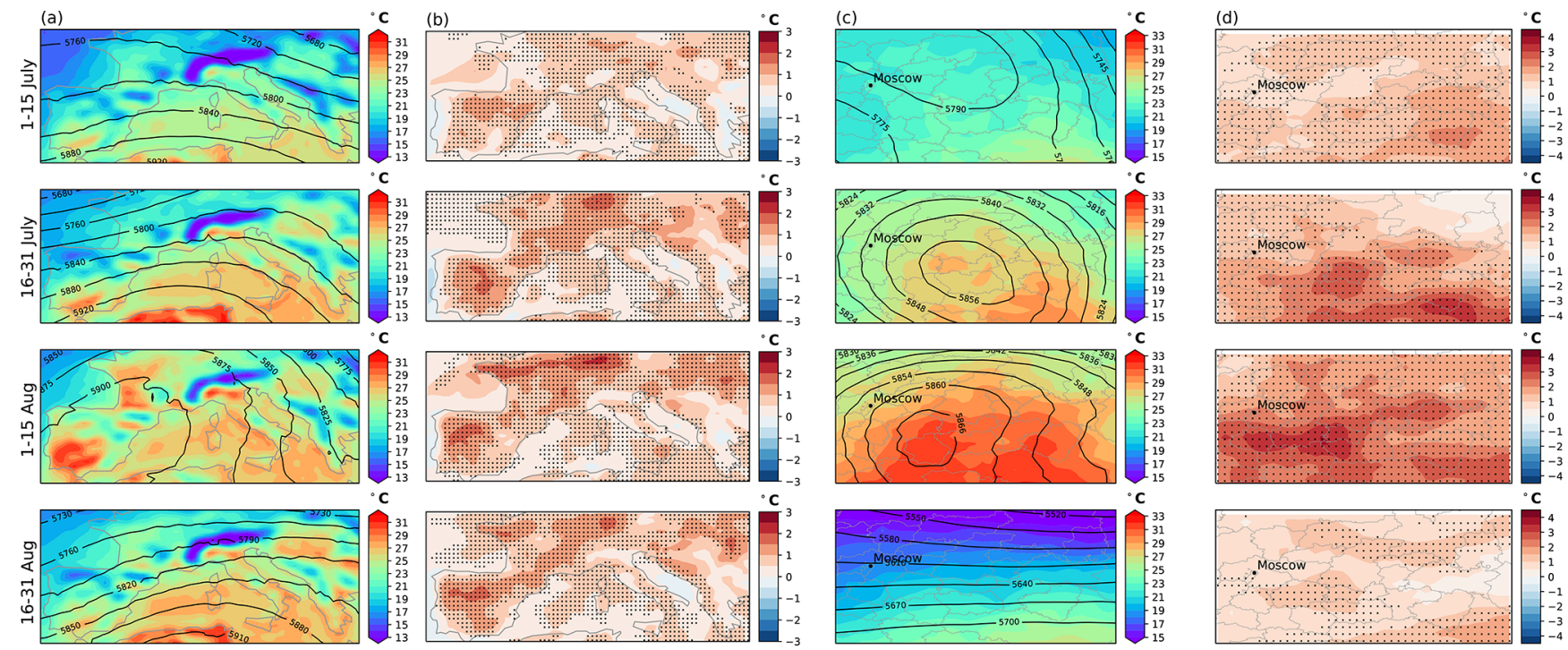

Figure 6. July and August divided into four half-month periods. Columns (a) and (b) show the European heatwave 2003, while columns (c) and (d) show the Russian heatwave 2010. In columns (a) and (c), the factual geopotential height at $z_{500}$ [m] is shown as black contour lines, while temperatures at $2 \mathrm{~m}$ height $\left[{ }^{\circ} \mathrm{C}\right]$ are shown as shaded fields. In columns (b) and (d), the differences in $2 \mathrm{~m}$ temperature $\left[{ }^{\circ} \mathrm{C}\right]$ between the factual and counterfactual simulations are shown as shaded fields. Stippling shows where all the factual members are $>0.1{ }^{\circ} \mathrm{C}$ above all the counterfactual members for that grid point. Note that the Russian domain is smaller; therefore the stippling has a different spacing than in the European domain.

erage. This value of $0.6^{\circ} \mathrm{C}$ is in line with the global-mean warming. ERA-Interim and the factual members show a strong correlation in time, although the ERA-Interim temperatures are higher especially in June and during the heatwave in the first half of August. The factual temperatures exceed the 95th percentile several times in June-August. In August, the exceedance lasts for almost 2 weeks, whereas in June it does so for approximately 1 week. The counterfactual temperatures are not quite so extreme; they exceed the 95th percentile only for a few days at a time in June and August. Nevertheless, it is clear that there would have been a European heatwave in 2003 even without climate change, albeit with less extreme temperatures. This analysis thus supports both of the perspectives on the event discussed earlier whilst providing a daily resolution of the climate change attribution.

The temperature differences between the factual and counterfactual ensembles are spatially nonuniform over Europe. In Fig. 6a the factual members' average of the $2 \mathrm{~m}$ temperature and of the geopotential height $\left(z_{500}\right)$ show the meteorological situation averaged over half-month periods following García-Herrera et al. (2010). Figure 6b shows the local differences in $2 \mathrm{~m}$ temperatures between the counterfactual and factual ensemble averages. Stippling is added to each grid point where all the three factual members are at least $0.1^{\circ} \mathrm{C}$ warmer than all the counterfactual members. There is strong local variance, especially during the heatwave in the first half of August, with differences of up to $2.5^{\circ} \mathrm{C}$. In the first period (1-15 July) the local differences are generally modest, except in northern Spain, where they reach $1.5-2^{\circ} \mathrm{C}$. In the second and third half-month periods (16-31 July, 1-15 August), the temperatures in the factual simulations can locally be up to $2-2.5^{\circ} \mathrm{C}$ higher than in the counterfactual simulations, with the differences spread over a large area including Spain, Portugal, France, Germany, Hungary, and Romania. During the period 1-15 August, which according to Fig. 5a was the peak of the heatwave, the hottest area in Europe (Fig. 6a) is located in south-west France and southern Iberia. However the largest differences between the factual and counterfactual simulations (up to $2.5^{\circ} \mathrm{C}$ ) are found to the north of both of these regions, suggesting a shift in the peak temperature. In the second half of August, there are still some strong temperature differences visible over most of these regions, although the differences over western France have dampened.

As noted earlier, the dryness of the soil has been identified as an important contributing factor to the 2003 heatwave. Our interest here, however, is on whether the soil wetness differed between factual and counterfactual conditions. In Fig. 7a we see a very similar decline in soil wetness for both the factual and counterfactual ensemble members from May until the end of August. The counterfactual simulations start out with somewhat higher soil wetness than the factual simulations, but over the course of the summer the values of both sets of simulations move closer towards each other so that by August the ensembles are close together. Thus it does not appear that climate change had a first-order impact on soil wetness in this case. 


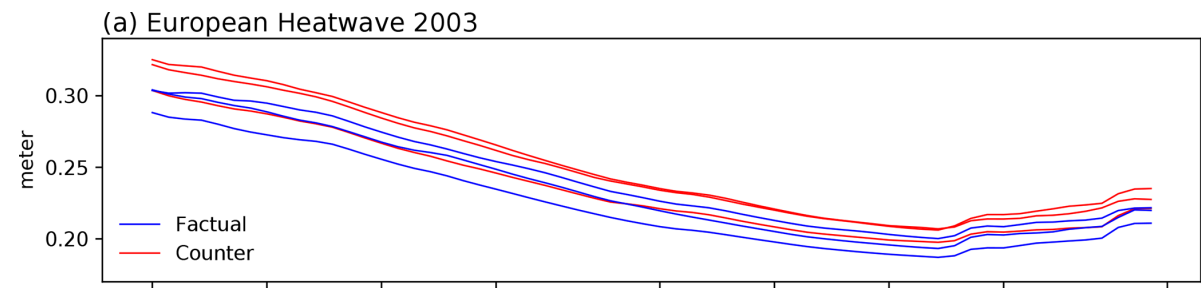

(b) Russian Heatwave 2010

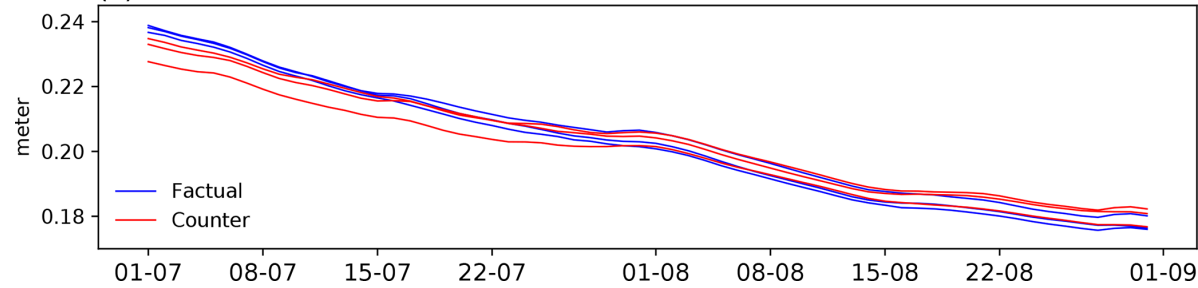

Figure 7. Average soil wetness in the root zone [m] averaged over Europe in 2003 and Russia in 2010 during July and August of each year. The factual simulations are shown in blue and the counterfactual simulations in red.

\subsection{Russian heatwave 2010}

In August 2010 western Russia was hit by an unprecedented heatwave caused by a large quasi-stationary anticyclonic circulation, or blocking (Galarneau et al., 2012; Grumm, 2011; Matsueda, 2011). It was a heatwave that broke all records such as temperature anomalies during both day and night, temporal duration, and spatial extent. The effect of soil wetness, or rather the lack thereof, on the magnitude of the temperatures was profound (Lau and Kim, 2012; Rasmijn et al., 2018; Wehrli et al., 2019; Bastos et al., 2014). The 2010 Russian heatwave is considered the most extreme heatwave in Europe on record (Russo et al., 2015). Approximately 50000 lives were lost, $5000 \mathrm{~km}^{2}$ forest burned, $25 \%$ of the crop failed and over USD 15 billion worth of economic damage was recorded due to this heatwave (Barriopedro et al., 2011; Lau and Kim, 2012; Otto et al., 2012; Rasmijn et al., 2018). In some of the attribution studies, the heatwave was primarily attributed to internal variability as the dynamical situation strongly depended on the El Niño-Southern Oscillation (ENSO) being in a La Niña state (Dole et al., 2011; Russo et al., 2014; Schneidereit et al., 2012). However, the likelihood of the temperatures reaching such extreme values has also been assessed as being significantly exacerbated by climate change (Otto et al., 2012; Rahmstorf and Coumou, 2011). As with the previous example, the storyline approach can represent both of these perspectives. Moreover, it overcomes the limitation that the climate models used to perform probabilistic event attribution generally have trouble reproducing a blocking situation correctly (Trenberth and Fasullo, 2012; Watanabe et al., 2013).

In Fig. 5b, the daily evolution of the domain-averaged temperature at $2 \mathrm{~m}$ height for each of the ensemble members is shown in comparison to ECHAM_SN 2010, the ECHAM_SN 5th-95th-percentile climatological temperatures (1985-2015), and ERA-Interim. ERA-Interim temper- atures correlate highly with the counterfactual members, though are somewhat higher at the end of June and beginning of July, and decline much more rapidly following the heatwave halfway through August. Starting after the second half of July, both the factual and counterfactual temperatures exceed the 95th-percentile climatological temperature, peak around 8 August, and return to climatological temperatures around 17 August. This analysis shows that this would have been an unprecedented event even without climate change. The differences between the factual and counterfactual temperatures during the core of the heatwave are noticeably higher (about $2^{\circ} \mathrm{C}$ ) than in the European heatwave 2003, as is the spread between the ensemble members. In contrast to the European case, the anthropogenic warming during the core of the heatwave is considerably higher than the global-mean warming. We attribute both aspects - the greatly enhanced anthropogenic warming and the larger internal variability to the fact that the Russian domain is much farther inland than the European domain, and thus the blocking conditions cut off the influence of the SST forcing and allow a direct radiative effect of GHG increases (Wehrli et al., 2019). Note that western Russia is known for having large internal variability (Dole et al., 2011; Russo et al., 2014; Schneidereit et al., 2012), which is clearly apparent in our results. It is also the case that the Russian domain is smaller than the European domain by a factor of 3.4 , which would furthermore tend to increase the variability in the domain-averaged temperature shown in Fig. 5.

The range of temperature differences between factual and counterfactual simulations reach values up to $4{ }^{\circ} \mathrm{C}$ locally, as seen in Fig. 6d. Note that the scale for the Russian heatwave reaches up to $4.5^{\circ} \mathrm{C}$, whereas the scale for the European heatwave reaches only $3^{\circ} \mathrm{C}$. In the first half-month period (1-15 July), when the heatwave had not yet started, the local temperature differences are between $0.5-2.5^{\circ} \mathrm{C}$, with the maximum differences in the south-east of the domain. 

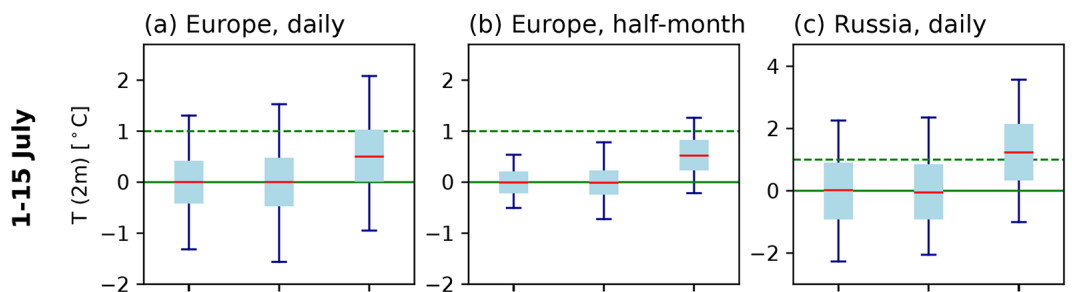

(d) Russia, half-month
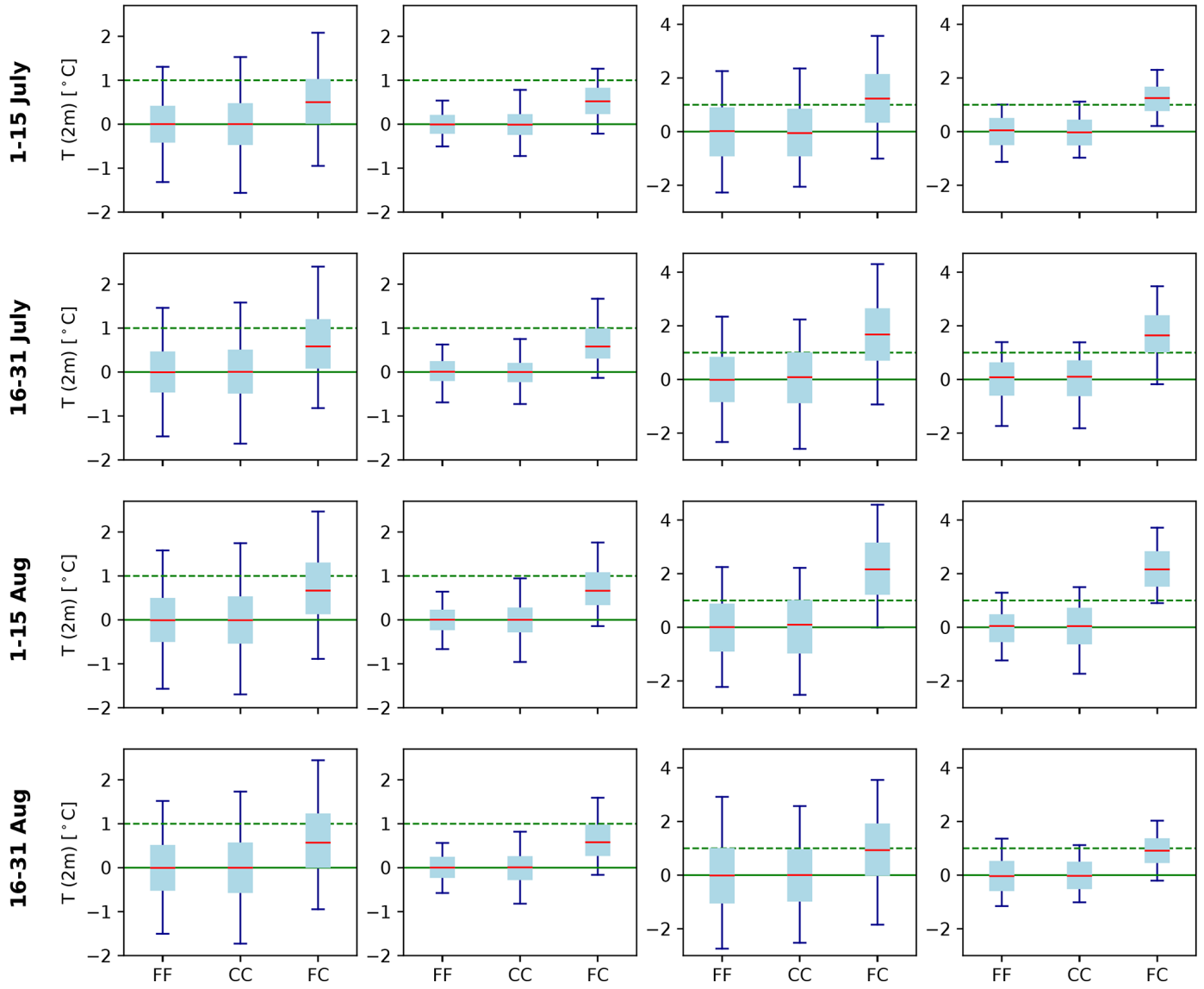

Figure 8. Distributions across grid points of differences between ensemble members in temperature at $2 \mathrm{~m}$ height $\left[{ }^{\circ} \mathrm{C}\right]$, separated into the four half-monthly periods. FF: differences between pairs of factual members; CC: differences between pairs of counterfactual members; FC: differences between pairs of factual and counterfactual members. The boxes represent the 25th-to-75th-percentile range of the distributions, the red lines represent the 50th percentiles (the median), and the blue bars indicate the 5th-to-95th-percentile range. The dashed horizontal line indicates $1^{\circ} \mathrm{C}$ for reference. Columns (a) and (b) are for the European 2010 heatwave, and columns (c) and (d) for the Russian 2010 heatwave. Note the different vertical scales for the two events. Columns (a) and (c) show the differences in daily averages, and columns (b) and (d) show the differences in half-monthly averages.

The temperature differences are largest in the core of the block region, reaching up to $3.5^{\circ} \mathrm{C}$ in the south-east in the second period (16-31 July) and up to $4^{\circ} \mathrm{C}$ in the south, below Moscow, in the third period (1-15 August). The block broke in the fourth period (16-31 August) and resulted in a virtual elimination of the temperature difference. In contrast to the European heatwave 2003, here the biggest temperature differences between factual and counterfactual are found in the regions with the highest temperatures.

As with the European heatwave 2003, the differences in soil wetness do not appear to be of first-order importance to explain the temperature differences between the factual and counterfactual simulations. In Fig. 7b the soil wetness in the factual simulations is seen to decrease somewhat more rapidly than in the counterfactual, which could be due to the higher surface temperature and thus greater evaporation of soil moisture. However, the soil wetness values are over- lapping and even cross each other in the beginning of August. These findings are in agreement with those of Hauser et al. (2016), who reproduced the Russian heatwave under 1960 conditions and found that the dry conditions occurred there too, thus concluding they found no direct link between the drought conditions and climate change. It must be emphasized that this is not to downplay in any way the impact of soil wetness on the event itself, which has been well established in the literature. It is only to indicate that the impact would have been there even without climate change.

\subsection{Signal-to-noise analysis}

The temperature differences found between the factual and counterfactual simulations are meaningful if they are outside of the internal variability within each ensemble. A different way of saying this is that the differences are meaningful if the two ensembles are distinguishable from each other. To assess 
this in a statistical manner, temperature differences between pairs of factual members (FF), pairs of counterfactual members (CC), and factual-counterfactual pairs (FC) are plotted for each half-month period in Fig. 8. The FF and CC pairs have a median close to 0 and represent the noise level; in both cases there are three pairs (F1-F2, F2-F3, F3-F1; C1$\mathrm{C} 2, \mathrm{C} 2-\mathrm{C} 3, \mathrm{C} 3-\mathrm{C} 1)$. The FC pairs contain the signal; here there are nine pairs $(\mathrm{F} 1-\mathrm{C} 1, \mathrm{~F} 2-\mathrm{C} 2, \mathrm{~F} 3-\mathrm{C} 3, \mathrm{~F} 2-\mathrm{C} 1, \mathrm{~F} 3-\mathrm{C} 2$, F1-C3, F3-C1, F1-C2, F2-C3). Each box plot represents the distribution of $2 \mathrm{~m}$ temperature differences across the pairs and across all grid points. The half-monthly panels represent distributions of half-month-averaged values, and the daily panels represent distributions of daily values within the halfmonth period.

The daily differences for the European heatwave (Fig. 8a) show a median value of about $0.6^{\circ} \mathrm{C}$, irrespective of whether the time frame is during the heatwave itself or directly before or directly after it, consistent with Fig. 5a. Although these are not really probability distributions (since they include contributions from different locations within the domain), we can use the inter-quartile ranges as measures of signal and noise. The median difference for $\mathrm{FC}$ is above the 75 th percentile of both $\mathrm{CC}$ and FF for daily values, giving confidence that our results are clearly above the noise level. Half-monthly time averages (Fig. 8b) produce nearly identical median values, but we see that the spread is much smaller, as expected. The 25 th percentile of FC now lies above the 75th percentile of the $\mathrm{CC}$ and $\mathrm{FF}$ boxes.

The differences between $\mathrm{CF}$ and either FF or CC for the Russian heatwave (Fig. 8c and d) are clearly larger than for the European heatwave and in contrast to the European case vary substantially between the different periods. Consistent with Fig. 5b, in the periods outside of the core of the heatwave (1-15 July, 16-31 August) the median difference between $\mathrm{FC}$ is about $1{ }^{\circ} \mathrm{C}$. Inside the core heatwave period (16-31 July, 1-15 August), however, the median difference is more like $2{ }^{\circ} \mathrm{C}$, reaching $2.2^{\circ} \mathrm{C}$ for $1-15$ August. During this latter period the 5 th-percentile whisker of half-monthly FC differences is above the 75th percentile of FF and CC, which is a very strong signal indeed. When looking at the results for individual members, the larger internal variability within the Russian domain (apparent also in Fig. 5b) is clearly visible (not shown), as compared with the European case.

\section{Discussion and conclusion}

We have presented a detailed description and assessment of a global spectrally nudged storyline methodology to quantify the role of known thermodynamic aspects of climate change in specific extreme weather events. In this methodology, the particular dynamical conditions leading to the event are taken as given, i.e. are regarded as random, and the attribution is therefore highly conditional. Thus, as with all such storyline approaches to extreme-event attribution, the effect of climate change on the occurrence likelihood of those dynamical conditions is not assessed. In that respect, this approach is complementary to the more widely used probabilistic event attribution. However, since most results of probabilistic event attribution appeal in any case to the known thermodynamic aspects of climate change, it can be argued that not much is lost in the storyline approach, yet much is gained by the specificity. This is especially the case for extreme events whose dynamical conditions are not well represented in climate models, e.g. blocking. Spectral nudging enables the reproduction of extreme events with their particular dynamical details, allowing the same dynamical events to be reproduced in simulations with different boundary conditions and thereby achieving a high signal-to-noise ratio of the climate change effect. The combination of both methods - global spectral nudging and the storyline method - thus presents a way to quantify, in great detail, the role of known thermodynamic aspects of climate change, together with the specific dynamical conditions, in selected extreme events which happened in the recent past. This can help reconcile the sometimes different perspectives on those events that appear in the literature (some emphasizing climate change, others emphasizing internal variability).

We illustrated the method by applying it to two extreme events that have been the subject of much study: the European heatwave of 2003 and the Russian heatwave of 2010. By using a small ensemble of both factual and counterfactual simulations, we were able to determine a noise level for our analysis. This revealed that the (conditional) signal of climate change is determinable at both daily timescales and local spatial scales. It follows that our methodology could be used to drive climate impact models and thus perform realistic stress-testing of resilience strategies. With regard to the two heatwave examples, our analysis revealed a striking contrast between the two events. In the European heatwave of 2003, the effect of climate change was to increase temperatures across Europe by about the global-mean warming level throughout the summer, and the heatwave was simply the dynamical event riding on top of that. In the Russian heatwave of 2010, in contrast, the effect of climate change was much higher than the global warming level and was particularly enhanced, approximately threefold, during the peak of the heatwave. We interpret this difference as reflecting the role of direct GHG radiative forcing, which can become apparent when air masses are cut off from marine influence. However, further analysis would be required to confirm this hypothesis.

It is not possible to make a direct comparison between our results and probabilistic attribution of these heatwaves because they are answering different questions, and the conditionalities are quite different. However, from a methodological perspective it is useful to contrast the nature of the attribution statements that can be made using the different methods. We do this in Table 2 for the case of the Russian 2010 
Table 2. Example of attribution statements that are possible using the probabilistic and storyline approaches for the case of the 2010 Russian heatwave.

\begin{tabular}{ll}
\hline $\begin{array}{l}\text { Probabilistic attribution } \\
\text { (based on results from }\end{array}$ & $\begin{array}{l}\text { Averaged over the Russian domain and over the month of July, temperatures in } \\
\text { Otto et al., 2012) }\end{array}$ \\
& $\begin{array}{l}\text { Tariability, and } 1{ }^{\circ} \mathrm{C} \text { was due to anthropogenic climate change. } \\
\text { The heatwave represented a 1-in-33-year event, which was } 3 \text { times more } \\
\text { likely than it would have been in the } 1960 \mathrm{~s} \text {. }\end{array}$ \\
\hline $\begin{array}{l}\text { Storyline attribution } \\
\text { (based on present results) }\end{array}$ & $\begin{array}{l}\text { Averaged over the Russian domain, temperatures in } 2010 \text { steadily increased from } \\
\text { the } 1985-2015 \text { climatology through the month of July until about } 10 \text { August, then } \\
\text { rapidly returned to climatology. }\end{array}$ \\
& $\begin{array}{l}\text { The domain-averaged heatwave reached } 10{ }^{\circ} \mathrm{C} \text { above the } 1985-2015 \text { climatology } \\
\text { in early August, of which } 8^{\circ} \mathrm{C} \text { was due to internal variability, and } 2{ }^{\circ} \mathrm{C} \text { was due to } \\
\text { anthropogenic climate change. }\end{array}$ \\
& $\begin{array}{l}\text { The anthropogenic component of the warming reached } 4{ }^{\circ} \mathrm{C} \text { in the region to the } \\
\text { south of Moscow during the first half of August, where it exacerbated the already } \\
\text { warm temperatures there. }\end{array}$ \\
\hline
\end{tabular}

heatwave. Having said that, there is a continuum between storyline and probabilistic approaches (Shepherd, 2016), and it is possible to imagine intermediate set-ups which would provide a seamless connection between event attribution and probabilistic weather prediction (NAS, 2016). These would need to involve large ensembles (to calculate conditional probabilities) and pay more attention to the self-consistency of how the counterfactual conditions are imposed. An example is the recent use of an operational subseasonal-toseasonal prediction system, which involves modifying the atmospheric state and land surface conditions as well as the SSTs in generating the counterfactual (Wang et al., 2020).

The nudged global storyline method is an important step towards a holistic approach within the attribution of individual extreme events, which can quantify the role of both dynamical variability and known thermodynamic aspects of climate change and the interplay between them in great spatiotemporal detail. As shown by Wehrli et al. (2020), the method can easily be expanded to a larger number of storylines for both past and future. The method could also be applied to other extreme events affected thermodynamically by climate change such as tropical cyclones (Feser and Barcikowska, 2012). Our future applications are, therefore, intended to cover a wide variety of extreme events over the historical record.

Code and data availability. The ECHAM6.1 global atmospheric model is available from the Max Planck Institute for Meteorology (MPI-M) website: https://code.mpimet.mpg.de/ projects/mpi-esm-users/files (last access: 15 January 2021) (Giorgetta et al., 2021). The CMIP6 historical simulation data are archived at the World Data Centre for Climate (WDCC): https://cera-www.dkrz.de/WDCC/ui/cerasearch/entry?acronym=
RCM_CMIP6_Historical-HR (last access: 15 January 2021) (Schupfner, 2021). For analysis we have used the open-access Python packages.

Author contributions. LvG wrote the article, ran the simulations, and analysed their results. FF and TGS conceived the study and contributed to the writing and the interpretation of the results.

Competing interests. The authors declare that they have no conflict of interest.

Acknowledgements. We would like to thank Sebastian Rast from the Max Planck Institute for Meteorology (MPI-M) in Hamburg for his technical support in applying spectral nudging in the ECHAM6 model and Matthias Bittner and Wolfgang Müller from MPI-M for providing ECHAM6 CMIP6 data. Simulations were carried out on the MISTRAL supercomputer at the German Climate Computing Centre (DKRZ), with technical support from Irina Fast. This work is a contribution to the "Helmholtz Climate Initiative REKLIM" (Regional Climate Change), a joint research project of the Helmholtz Association of German Research Centres (HGF), as well as to the European Research Council advanced grant "Understanding the atmospheric circulation response to climate change" (grant no. 339390). The authors would like to thank Francis Zwiers and an anonymous reviewer for their thoughtful and constructive comments which helped improve the manuscript.

Financial support. This research has been supported by the European Research Council (grant no. 339390). 
The article processing charges for this open-access publication were covered by a Research

Centre of the Helmholtz Association.

Review statement. This paper was edited by Joaquim G. Pinto and reviewed by Francis Zwiers and one anonymous referee.

\section{References}

Barriopedro, D., Fischer, E. M., Luterbacher, J., Trigo, R., and Garcia-Herrera, R.: The Hot Summer of 2010: Redrawing the Temperature Record Map of Europe, Science, 332, 220-224, https://doi.org/10.1126/science.1201224, 2011.

Bastos, A., Gouveia, C. M., Trigo, R. M., and Running, S. W.: Analysing the spatio-temporal impacts of the 2003 and 2010 extreme heatwaves on plant productivity in Europe, Biogeosciences, 11, 3421-3435, https://doi.org/10.5194/bg-11-34212014, 2014.

Black, E., Blackburn, M., Harrison, G., Hoskins, B., and Methven, J.: Factors contributing to the summer 2003 European heatwave, Weather, 59, 217-223, https://doi.org/10.1256/wea.74.04, 2004.

Bony, S., Bellon, G., Klocke, D., Sherwood, S., Fermepin, S., and Denvil, S.: Robust direct effect of carbon dioxide on tropical circulation and regional precipitation, Nat. Geosci., 6, 447-451, https://doi.org/10.1038/ngeo1799, 2013.

Cattiaux, J., Vautard, R., Cassou, C., Yiou, P., Masson-Delmotte, V., and Codron, F.: Winter 2010 in Europe: A cold extreme in a warming climate, Geophys. Res. Lett., 37, L20704, https://doi.org/10.1029/2010GL044613, 2010.

Ciais, P., Reichstein, M., Viovy, N., Granier, A., Ogee, J., Allard, V., Aubinet, M., Buchmann, N., Bernhofer, C., Carrara, A., Chevallier, F., De Noblet, N., Friend, A. D., Friedlingstein, P., Grunwald, T., Heinesch, B., Keronen, P., Knohl, A., Krinner, G., Loustau, D., Manca, G., Matteucci, G., Miglietta, F., Ourcival, J. M., Papale, D., Pilegaard, K., Rambal, S., Seufert, G., Soussana, J. F., Sanz, M. J., Schulze, E. D., Vesala, T., and Valentini, R.: Europe-wide reduction in primary productivity caused by the heat and drought in 2003, Nature, 437, 529-533, https://doi.org/10.1038/nature03972, 2005.

Dee, D. P., Uppala, S. M., Simmons, A. J., Berrisford, P., Poli, P., Kobayashi, S., Andrae, U., Balmaseda, M. A., Balsamo, G., Bauer, P., Bechtold, P., Beljaars, A. C. M., van de Berg, L., Bidlot, J., Bormann, N., Delsol, C., Dragani, R., Fuentes, M., Geer, A. J., Haimberger, L., Healy, S. B., Hersbach, H., Holm, E. V., Isaksen, L., Kallberg, P., Kohler, M., Matricardi, M., McNally, A. P., Monge-Sanz, B. M., Morcrette, J. J., Park, B. K., Peubey, C., de Rosnay, P., Tavolato, C., Thepaut, J. N., and Vitart, F.: The ERA-Interim reanalysis: configuration and performance of the data assimilation system, Q. J. Roy. Meteorol. Soc., 137, 553597, https://doi.org/10.1002/qj.828, 2011.

Deser, C., Terray, L., and Phillips, A. S.: Forced and Internal Components of Winter Air Temperature Trends over North America during the past 50 Years: Mechanisms and Implications, J. Climate, 29, 2237-2258, https://doi.org/10.1175/jcli-d-15-0304.1, 2016.

Dole, R., Hoerling, M., Perlwitz, J., Eischeid, J., Pegion, P., Zhang, T., Quan, X. W., Xu, T. Y., and Murray, D.: Was there a basis for anticipating the 2010 Russian heat wave?, Geophys. Res. Lett., 38, L06702, https://doi.org/10.1029/2010g1046582, 2011.

Feser, F. and Barcikowska, M.: The influence of spectral nudging on typhoon formation in regional climate models, Environ. Res. Lett., 7, 014024, https://doi.org/10.1088/1748-9326/7/1/014024, 2012.

Feudale, L. and Shukla, J.: Influence of sea surface temperature on the European heat wave of 2003 summer. Part I: an observational study, Clim. Dynam., 36, 1691-1703, https://doi.org/10.1007/s00382-010-0788-0, 2011a.

Feudale, L. and Shukla, J.: Influence of sea surface temperature on the European heat wave of 2003 summer Part II: a modeling study, Clim. Dynam., 36, 1705-1715, https://doi.org/10.1007/s00382-010-0789-z, 2011b.

Fink, A. H., Brücher, T., Krüger, A., Leckebusch, G. C., Pinto, J. G., and Ulbrich, U.: The 2003 European summer heatwaves and drought-synoptic diagnosis and impacts, Weather, 59, 209-216, https://doi.org/10.1256/wea.73.04, 2004.

Fischer, E. M., Seneviratne, S. I., Vidale, P. L., Lüthi, D., and Schär, C.: Soil moisture - Atmosphere interactions during the 2003 European summer heat wave, J. Climate, 20, 5081-5099, https://doi.org/10.1175/jcli4288.1, 2007.

Galarneau, T. J., Hamill, T. M., Dole, R. M., and Perlwitz, J.: A Multiscale Analysis of the Extreme Weather Events over Western Russia and Northern Pakistan during July 2010, Mon. Weather Rev., 140, 1639-1664, https://doi.org/10.1175/mwr-d11-00191.1, 2012.

García-Herrera, R., Díaz, J., Trigo, R. M., Luterbacher, J., and Fischer, E. M.: A review of the European summer heat wave of 2003, Crit. Rev. Environ. Sci. Technol., 40, 267-306, https://doi.org/10.1080/10643380802238137, 2010.

Giorgetta, M. A., Roeckner, E., Mauritsen, T., Bader, J., Crueger, T., Esch, M., Rast, S., Kornblueh, L., Schmidt, H., Kinne, S., Hohenegger, C., Möbis, B., Krismer, T., Wieners, K.H., and Stevens, B.: ECHAM 6.1.00, available at: https:// code.mpimet.mpg.de/projects/mpi-esm-users/files, last access: 15 January 2021.

Grumm, R. H.: The central European and Russian heat event of July-August 2010, B. Am. Meteorol. Soc., 92, 1285-1296, https://doi.org/10.1175/2011BAMS3174.1, 2011.

Hannart, A., Pearl, J., Otto, F. E. L., Naveau, P., and Ghil, M.: Causal Counterfactual Theory for the Attribution of Weather and Climate-Related Events, B. Am. Meteorol. Soc., 97, 99-110, https://doi.org/10.1175/bams-d-14-00034.1, 2016.

Hauser, M., Orth, R., and Seneviratne, S. I.: Role of soil moisture versus recent climate change for the 2010 heat wave in western Russia, Geophys. Res. Lett., 43, 2819-2826, https://doi.org/10.1002/2016gl068036, 2016.

Horton, D. E., Johnson, N. C., Singh, D., Swain, D. L., Rajaratnam, B., and Diffenbaugh, N. S.: Contribution of changes in atmospheric circulation patterns to extreme temperature trends, Nature, 522, 465-469, https://doi.org/10.1038/nature14550, 2015.

Hoskins, B. and Woollings, T.: Persistent extratropical regimes and climate extremes, Curr. Clim. Change Rep., 1, 115-124, https://doi.org/10.1007/s40641-015-0020-8, 2015.

Hurrell, J. W., Hack, J. J., Shea, D., Caron, J. M., and Rosinski, J.: A new sea surface temperature and sea ice boundary dataset for the Community Atmosphere Model, J. Climate, 21, 5145-5153, https://doi.org/10.1175/2008JCLI2292.1, 2008. 
IPCC: Managing the Risks of Extreme Events and Disasters to Advance Climate Change Adaptation, in: A Special Report of Working Groups I and II of the Intergovernmental Panel on Climate Change, edited by: Field, C. B., Barros, V., Stocker, T. F., Qin, D., Dokken, D. J., Ebi, K. L., Mastrandrea, M. D., Mach, K. J., Plattner, G.-K., Allen, S. K., Tignor, M., and Midgley, P. M., Cambridge University Press, Cambridge, UK, and New York, NY, USA, 582 pp., 2012.

IPCC - Inter-governmental Panel on Climate Change: Summary for Policymakers, Global Warming of $1.5^{\circ} \mathrm{C}$ : An IPCC Special Report on the Impacts of Global Warming of $1.5^{\circ} \mathrm{C}$ Above Preindustrial Levels and Related Global Greenhouse Gas Emission Pathways, in: the Context of Strengthening the Global Response to the Threat of Climate Change, Sustainable Development, and Efforts to Eradicate Poverty, edited by: Masson-Delmotte, V., Zhai, P., Pörtner, H.-O., Roberts, D., Skea, J., Shukla, P., Pirani, A., Moufouma-Okia, W., Péan, C., Pidcock, R., Connors, S., Matthews, J., Chen, Y., Zhou, X., Gomis, M., Lonnoy, E., Maycock, T., Tignor, M., and Watefield, T., World Meteorological Organization, Geneva, Switzerland, 32 pp., 2018.

Jeuken, A. B. M., Siegmund, P. C., Heijboer, L. C., Feichter, J., and Bengtsson, L.: On the potential of assimilating meteorological analyses in a global climate model for the purpose of model validation, J. Geophys. Res.-Atmos., 101, 16939-16950, https://doi.org/10.1029/96jd01218, 1996.

Kalnay, E., Kanamitsu, M., Kistler, R., Collins, W., Deaven, D., Gandin, L., Iredell, M., Saha, S., White, G., Woollen, J., Zhu, Y., Chelliah, M., Ebisuzaki, W., Higgins, W., Janowiak, J., Mo, K. C., Ropelewski, C., Wang, J., Leetmaa, A., Reynolds, R., Jenne, R., and Joseph, D.: The NCEP/NCAR 40-year reanalysis project, B. Am. Meteorol. Soc., 77, 437-471, https://doi.org/10.1175/15200477(1996)077<0437:Tnyrp>2.0.Co;2, 1996.

Kim, J. E. and Hong, S. Y.: A Global Atmospheric Analysis Dataset Downscaled from the NCEP-DOE Reanalysis, J. Climate, 25, 2527-2534, https://doi.org/10.1175/jcli-d-11-00534.1, 2012.

Lau, W. K. M. and Kim, K. M.: The 2010 Pakistan Flood and Russian Heat Wave: Teleconnection of Hydrometeorological Extremes, J. Hydrometeorol., 13, 392-403, https://doi.org/10.1175/jhm-d-11-016.1, 2012.

Lloyd, E. A. and Oreskes, N.: Climate Change Attribution: When Is It Appropriate to Accept New Methods?, Earths Future, 6, 311325, https://doi.org/10.1002/2017ef000665, 2018.

Lloyd, E. A. and Shepherd, T. G.: Environmental catastrophes, climate change, and attribution, Ann. NY Acad. Sci., 1469, 105124, https://doi.org/10.1111/nyas.14308, 2020.

Luterbacher, J., Dietrich, D., Xoplaki, E., Grosjean, M., and Wanner, H.: European seasonal and annual temperature variability, trends, and extremes since 1500, Science, 303, 1499-1503, https://doi.org/10.1126/science.1093877, 2004.

Matsueda, M.: Predictability of Euro-Russian blocking in summer of 2010, Geophys. Res. Lett., 38, L06801, https://doi.org/10.1029/2010g1046557, 2011.

Meinshausen, M., Smith, S. J., Calvin, K., Daniel, J. S., Kainuma, M. L. T., Lamarque, J. F., Matsumoto, K., Montzka, S. A., Raper, S. C. B., Riahi, K., Thomson, A., Velders, G. J. M., and van Vuuren, D. P. P.: The RCP greenhouse gas concentrations and their extensions from 1765 to 2300, Climatic Change, 109, 213-241, https://doi.org/10.1007/s10584-011-0156-z, 2011.
Meredith, E. P., Semenov, V. A., Maraun, D., Park, W., and Chernokulsky, A. V.: Crucial role of Black Sea warming in amplifying the 2012 Krymsk precipitation extreme, Nat. Geosci., 8, 615-619, https://doi.org/10.1038/ngeo2483, 2015.

Miguez-Macho, G., Stenchikov, G. L., and Robock, A.: Spectral nudging to eliminate the effects of domain position and geometry in regional climate model simulations, J. Geophys. Res.-Atmos., 109, D13104, https://doi.org/10.1029/2003jd004495, 2004.

Miralles, D. G., Teuling, A. J., van Heerwaarden, C. C., and VilàGuerau de Arellano, J.: Mega-heatwave temperatures due to combined soil desiccation and atmospheric heat accumulation, Nat. Geosci., 7, 345-349, https://doi.org/10.1038/ngeo2141, 2014.

Müller, W. A., Jungclaus, J. H., Mauritsen, T., Baehr, J., Bittner, M., Budich, R., Bunzel, F., Esch, M., Ghosh, R., Haak, H., Ilyina, T., Kleine, T., Kornblueh, L., Li, H., Modali, K., Notz, D., Pohlmann, H., Roeckner, E., Stemmler, I., Tian, F., and Marotzke, J.: A Higher-resolution Version of the Max Planck Institute Earth System Model (MPIESM1.2-HR), J. Adv. Model. Earth Syst., 10, 1383-1413, https://doi.org/10.1029/2017ms001217, 2018.

Muthers, S., Laschewski, G., and Matzarakis, A.: The Summers 2003 and 2015 in South-West Germany: Heat Waves and Heat-Related Mortality in the Context of Climate Change, Atmosphere, 8, 224, https://doi.org/10.3390/atmos8110224, 2017.

NAS - National Academies of Sciences Engineering and Medicine: Attribution of Extreme Weather Events in the Context of Climate Change, The National Academies Press, Washington, D.C., https://doi.org/10.17226/21852, 2016.

Otto, F. E. L.: Attribution of Weather and Climate Events, Annu. Rev. Environ. Resour., 42, https://doi.org/10.1146/annurevenviron-102016-060847, 627-646, 2017.

Otto, F. E. L., Massey, N., van Oldenborgh, G. J., Jones, R. G., and Allen, M. R.: Reconciling two approaches to attribution of the 2010 Russian heat wave, Geophys. Res. Lett., 39, L04702, https://doi.org/10.1029/2011g1050422, 2012.

Patricola, C. M. and Wehner, M. F.: Anthropogenic influences on major tropical cyclone events, Nature, 563, 339-346, https://doi.org/10.1038/s41586-018-0673-2, 2018.

Pearl, J. and Mackenzie, D.: The book of Why: The new science of cause and effect, Basic Books, New York, 2018.

Pfahl, S., O'Gorman, P. A., and Fischer, E. M.: Understanding the regional pattern of projected future changes in extreme precipitation, Nat. Clim. Change, 7, 423-427, https://doi.org/10.1038/nclimate3287, 2017.

Rahmstorf, S. and Coumou, D.: Increase of extreme events in a warming world, P. Natl. Acad. Sci. USA, 108, 17905-17909, https://doi.org/10.1073/pnas.1101766108, 2011.

Rasmijn, L. M., van der Schrier, G., Bintanja, R., Barkmeijer, J., Sterl, A., and Hazeleger, W.: Future equivalent of 2010 Russian heatwave intensified by weakening soil moisture constraints, Nat. Clim. Change, 8, 381-385, https://doi.org/10.1038/s41558018-0114-0, 2018.

Rayner, N. A., Brohan, P., Parker, D. E., Folland, C. K., Kennedy, J. J., Vanicek, M., Ansell, T. J., and Tett, S. F. B.: Improved Analyses of Changes and Uncertainties in Sea Surface Temperature Measured In Situ since the Mid-Nineteenth Century: The HadSST2 Dataset, J. Climate, 19, 446-469, https://doi.org/10.1175/jcli3637.1, 2006. 
Reick, C. H., Raddatz, T., Brovkin, V., and Gayler, V.: Representation of natural and anthropogenic land cover change in MPI-ESM, J. Adv. Model. Earth Syst., 5, 459-482, https://doi.org/10.1002/jame.20022, 2013.

Russo, S., Dosio, A., Graversen, R. G., Sillmann, J., Carrao, H., Dunbar, M. B., Singleton, A., Montagna, P., Barbola, P., and Vogt, J. V.: Magnitude of extreme heat waves in present climate and their projection in a warming world, J. Geophys. Res.-Atmos., 119, 12500-12512, https://doi.org/10.1002/2014jd022098, 2014

Russo, S., Sillmann, J., and Fischer, E. M.: Top ten European heatwaves since 1950 and their occurrence in the coming decades, Environ. Res. Lett., 10, 124003, https://doi.org/10.1088/17489326/10/12/124003, 2015.

Schär, C., Frei, C., Lüthi, D., and Davies, H. C.: Surrogate climatechange scenarios for regional climate models, Geophys. Res. Lett., 23, 669-672, https://doi.org/10.1029/96GL00265, 1996.

Schär, C., Vidale, P. L., Lüthi, D., Frei, C., Häberli, C., Liniger, M. A., and Appenzeller, C.: The role of increasing temperature variability in European summer heatwaves, Nature, 427, 332336, https://doi.org/10.1038/nature02300, 2004.

Schneider, D. P., Deser, C., and Okumura, Y.: An assessment and interpretation of the observed warming of West Antarctica in the austral spring, Clim. Dynam., 38, 323-347, https://doi.org/10.1007/s00382-010-0985-x, 2012.

Schneidereit, A., Schubert, S., Vargin, P., Lunkeit, F., Zhu, X. H., Peters, D. H. W., and Fraedrich, K.: Large-Scale Flow and the Long-Lasting Blocking High over Russia: Summer 2010, Mon. Weather Rev., 140, 2967-2981, https://doi.org/10.1175/mwr-d11-00249.1, 2012.

Schubert-Frisius, M., Feser, F., von Storch, H., and Rast, S.: Optimal Spectral Nudging for Global Dynamic Downscaling, Mon. Weather Rev., 145, 909-927, https://doi.org/10.1175/mwr-d-160036.1, 2017.

Schupfner, M.: CMIP6 Scenario MIP DKRZ MPI-ESM12-HR historical - RCM-forcing data, available at: https://cera-www.dkrz.de/WDCC/ui/cerasearch/entry? acronym=RCM_CMIP6_Historical-HR, last access: 15 January 2021

Scinocca, J. F., Kharin, V. V., Jiao, Y., Qian, M. W., Lazare, M., Solheim, L., Flato, G. M., Biner, S., Desgagne, M., and Dugas, B.: Coordinated Global and Regional Climate Modeling, J. Climate, 29, 17-35, https://doi.org/10.1175/jcli-d-15-0161.1, 2015.

Screen, J. A. and Simmonds, I.: Increasing fall-winter energy loss from the Arctic Ocean and its role in Arctic temperature amplification, Geophys. Res. Lett., 37, L16707, https://doi.org/10.1029/2010GL044136, 2010.

Shepherd, T. G.: Dynamics, stratospheric ozone, and climate change, Atmos.-Ocean, 46, 117-138, https://doi.org/10.3137/ao.460106, 2008.

Shepherd, T. G.: Atmospheric circulation as a source of uncertainty in climate change projections, Nat. Geosci., 7, 703-708, https://doi.org/10.1038/ngeo2253, 2014.

Shepherd, T. G.: A Common Framework for Approaches to Extreme Event Attribution, Curr. Clim. Change Rep., 2, 28-38, https://doi.org/10.1007/s40641-016-0033-y, 2016.

Stevens, B., Giorgetta, M., Esch, M., Mauritsen, T., Crueger, T., Rast, S., Salzmann, M., Schmidt, H., Bader, J., Block, K., Brokopf, R., Fast, I., Kinne, S., Kornblueh, L., Lohmann, U., Pin- cus, R., Reichler, T., and Roeckner, E.: Atmospheric component of the MPI-M Earth System Model: ECHAM6, J. Adv. Model. Earth Syst., 5, 146-172, https://doi.org/10.1002/jame.20015, 2013.

Stott, P. A., Stone, D. A., and Allen, M. R.: Human contribution to the European heatwave of 2003, Nature, 432, 610-614, https://doi.org/10.1038/nature03089, 2004.

Stott, P. A., Christidis, N., Otto, F. E. L., Sun, Y., Vanderlinden, J. P., van Oldenborgh, G. J., Vautard, R., von Storch, H., Walton, P., Yiou, P., and Zwiers, F. W.: Attribution of extreme weather and climate-related events, Wiley Interdisciplin. Rev. - Clim. Change, 7, 23-41, https://doi.org/10.1002/wcc.380, 2016.

Trenberth, K. E. and Fasullo, J. T.: Climate extremes and climate change: The Russian heat wave and other climate extremes of 2010, J. Geophys. Res.-Atmos., 117, D17103, https://doi.org/10.1029/2012jd018020, 2012.

Trenberth, K. E., Fasullo, J. T., and Shepherd, T. G.: Attribution of climate extreme events, Nat. Clim. Change, 5, 725-730, https://doi.org/10.1038/nclimate2657, 2015.

Trigo, R. M., García-Herrera, R., Díaz, J., Trigo, I. F., and Valente, M. A.: How exceptional was the early August 2003 heatwave in France?, Geophys. Res. Lett., 32, L10701, https://doi.org/10.1029/2005gl022410, 2005.

van der Wiel, K., Selten, F. M., Bintanja, R., Blackport, R., and Screen, J. A.: Ensemble climate-impact modelling: extreme impacts from moderate meteorological conditions, Environ. Res. Lett., 15, 034050, https://doi.org/10.1088/1748-9326/ab7668, 2020 .

van Niekerk, A., Shepherd, T. G., Vosper, S. B., and Webster, S.: Sensitivity of resolved and parametrized surface drag to changes in resolution and parametrization, Q. J. Roy. Meteorol. Soc., 142, 2300-2313, https://doi.org/10.1002/qj.2821, 2016.

Vautard, R., Yiou, P., Otto, F., Stott, P., Christidis, N., Van Oldenborgh, G. J., and Schaller, N.: Attribution of humaninduced dynamical and thermodynamical contributions in extreme weather events, Environ. Res. Lett., 11, 114009, https://doi.org/10.1088/1748-9326/11/11/114009, 2016.

von Storch, H., Langenberg, H., and Feser, F.: A spectral nudging technique for dynamical downscaling purposes, Mon. Weather Rev., 128, 3664-3673, https://doi.org/10.1175/15200493(2000)128<3664:Asntfd>2.0.Co;2, 2000.

von Storch, H., Cavicchia, L., Feser, F., and Li, D. L.: The Concept of Large-Scale Conditioning of Climate Model Simulations of Atmospheric Coastal Dynamics: Current State and Perspectives, Atmosphere, 9, 337, https://doi.org/10.3390/atmos9090337, 2018.

Waldron, K. M., Paegle, J., and Horel, J. D.: Sensitivity of a spectrally filtered and nudged limitedarea model to outer model options, Mon. Weather Rev., 124, 529-547, https://doi.org/10.1175/15200493(1996)124<0529:Soasfa>2.0.Co;2, 1996.

Wallace, J. M., Fu, Q., Smoliak, B. V., Lin, P., and Johanson, C. M.: Simulated versus observed patterns of warming over the extratropical Northern Hemisphere continents during the cold season, P. Natl. Acad. Sci. USA, 109, 14337-14342, https://doi.org/10.1073/pnas.1204875109, 2012.

Wang, G., Hope, P., Lim, E. P., Hendon, H. H., and Arblaster, J. M.: An initialized attribution method of extreme 
events on subseasonal to seasonal time-scales, J. Climate, https://doi.org/10.1175/JCLI-D-19-1021.1, in press, 2020.

Watanabe, M., Shiogama, H., Imada, Y., Mori, M., Ishii, M., and Kimoto, M.: Event attribution of the August 2010 Russian heat wave, Scient. Online Lett. Atmos., 9, 65-68, https://doi.org/10.2151/sola.2013-015, 2013.

Wehrli, K., Guillod, B. P., Hauser, M., Leclair, M., and Seneviratne, S. I.: Identifying Key Driving Processes of Major Recent Heat Waves, J. Geophys. Res.-Atmos., 124, 11746-11765, https://doi.org/10.1029/2019JD030635, 2019.
Wehrli, K., Hauser, M., and Seneviratne, S. I.: Storylines of the 2018 Northern Hemisphere heatwave at pre-industrial and higher global warming levels, Earth Syst. Dynam., 11, 855-873, https://doi.org/10.5194/esd-11-855-2020, 2020.

Yoshimura, K. and Kanamitsu, M.: Dynamical global downscaling of global reanalysis, Mon. Weather Rev., 136, 2983-2998, https://doi.org/10.1175/2008mwr2281.1, 2008. 